\title{
Das lebendige Herbar
}

\section{Iris Ritzmann}

Prof. Dr. med. et lic. phil., Mitglied der Redaktion Medizingeschichte

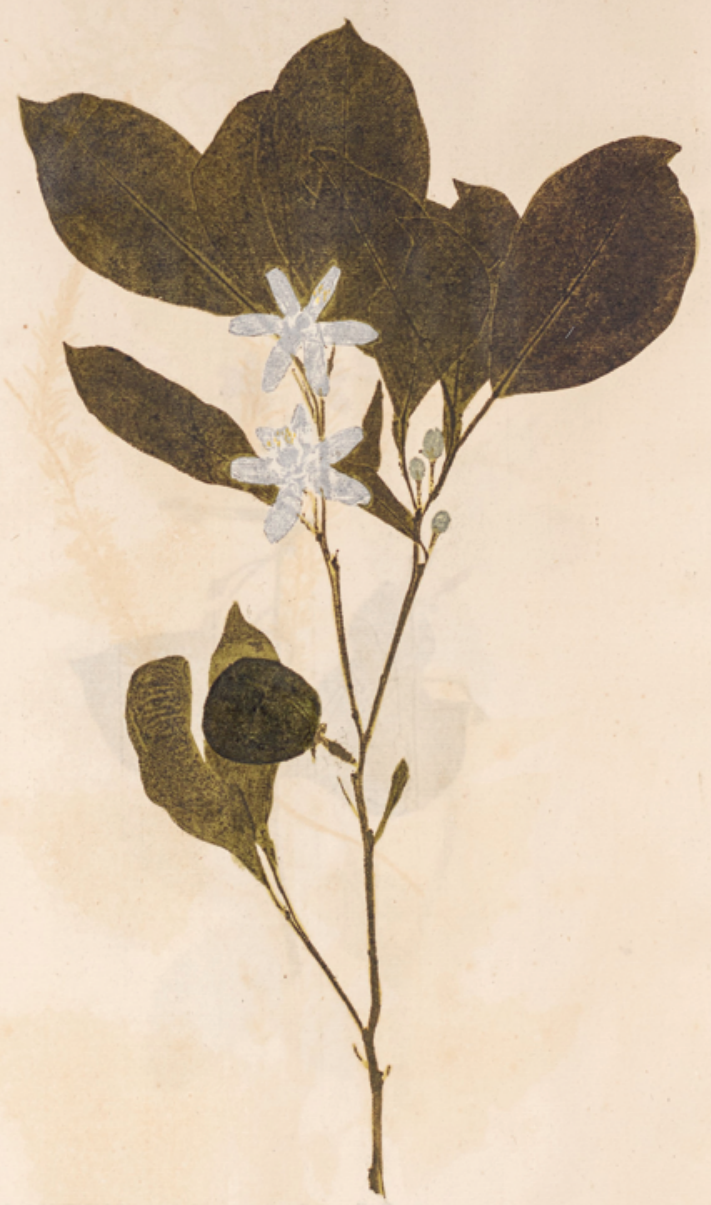

CITR VS petiolis alatis. Limn. S. P. 782. var. $\alpha$. Ludw. D. G. P. 792.

Aurantium. officin.

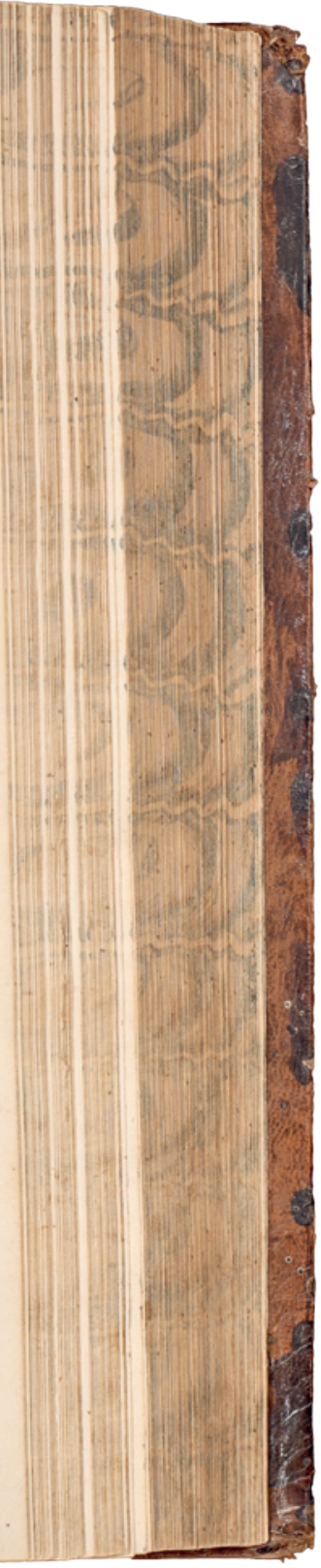

Johann Hieronymus Kniphof, 9. Centurion: Citrus aurantium oder Pomeranze, 1757-64. Sammlung Dr. Franz Käppeli.
Wie lässt sich eine Pflanze möglichst lebensecht abbilden? Diese Frage stellte sich der Erfurter Professor für Anatomie, Chirurgie und Botanik Johann Hieronymus Kniphof (1704-1763). Als Antwort publizierte er das «Herbarium vivum», ein lebendiges Herbar also. Natürlich lebte dieses Pflanzenbuch nicht, und dennoch kam der Autor dem Anliegen möglichst lebensechter Bilder ausgesprochen nahe. Das Gesamtwerk besteht aus zwölf "Centurien», die Kniphof je mit hundert Pflanzen bestückte. Unter diesen 1200 Blumen, Baum- und Strauchteilen, Kräutern und Gräsern stösst man im neunten Centurion auf eine Bitterorange, dargestellt mit Blättern, Blüten und sogar einer jungen Frucht. Trotz der starken Kolorierung ist die Oberflächenstruktur der Schale noch zu erkennen - ein wahres Kunstwerk, ein Ebenbild der ursprünglichen Frucht.

Hier war nicht etwa ein guter Zeichner oder ein begabter Kupferstecher am Werk. Statt einer Kupfer- oder Holzplatte wurden echte Pflanzen im Druckstock montiert und mit Druckerschwärze eingefärbt. Dieses Verfahren heisst «Naturdruck» und war schon Leonardo da Vinci bekannt. In der Aufklärung meinte wissenschaftliches Vorgehen in erster Linie akkurate Beobachtung und möglichst naturgetreue Wiedergabe. Kein Wunder, erlebte die direkte Drucktechnik gerade in dieser Epoche mit Kniphofs Herbarium vivum seine höchste Ausprägung.

Allerdings brachte der Naturdruck enorme Herausforderungen mit sich. Nach nur wenigen Drucken zerfiel die organische Vorlage, so dass sie durch eine analoge Pflanze ersetzt werden musste. Konkret wurden also für eine Auflage von hundert Exemplaren im Minimum zwanzig vergleichbare frische Pflanzen für jede einzelne Druckseite benötigt. Kniphof engagierte zahlreiche Helfer, die als botanische Sammler das Vorhaben möglich machten. Der Erfolg lässt sich in Korrespondenzen nachlesen, worin sich Wissenschaftler schon weit im Voraus auf das Erscheinen des nächsten Centurions freuten.

Erstaunlicherweise beinhalten diese Zusammenstellungen kaum Texte und erst recht keine neuen botanischen Erkenntnisse. Es ging um die exakte Visualisierung. Die Darstellung dreidimensionaler Pflanzenteile wie der runden Pomeranze mussten als eigentliche Highlights gewirkt haben. Wie Kniphof dabei vorging, ohne die Vorlage flach zu pressen, ist bis heute ungeklärt - es wird wohl sein Geheimnis bleiben. 